\title{
Structure and Properties of Microcrystalline Cellulose "Ceramics-Like" Composites Incorporated with $\mathrm{LaVO}_{4}: \mathrm{Sm}$ Oxide Compound
}

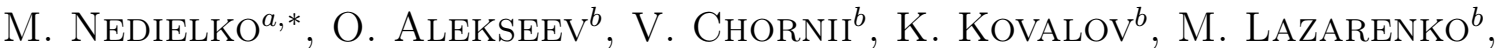 \\ S.G. Nedilko ${ }^{b}$, V. Scherbatskyi ${ }^{b}$, V. Boyko ${ }^{c}$ And V. Sheludko ${ }^{d}$ \\ ${ }^{a}$ Paton Electric Welding Institute of NASU, 11 Bozhenko Str., 03680 Kyiv, Ukraine \\ ${ }^{b}$ Taras Shevchenko National University of Kyiv, 64/13 Volodymyrska Str., 01601 Kyiv, Ukraine \\ ${ }^{c}$ National University of Life and Environmental Sciences of Ukraine, 15 Geroiv Oborony Str., 03041 Kyiv, Ukraine \\ ${ }^{d}$ Oleksandr Dovzhenko Hlukhiv National Pedagogical University, \\ 24 Kyjevo-Moskovs'ka Str., 41400, Hlukhiv, Ukraine \\ Composite samples based on microcrystalline cellulose matrix incorporated with micro/nanoparticles of \\ $\mathrm{La}_{0.7} \mathrm{Sm}_{0.3} \mathrm{VO}_{4}$ complex oxide were made by cool pressing procedure. Morphology, crystallinity and character- \\ istic luminescence and dielectric properties of the composites were studied. Their morphology can be described as \\ "ceramics-like" type, as it consists of cellulose plates and embedded oxide particles. Luminescence spectra of the \\ composites covers the range of the whole visible light, 350-750 nm, and comprises both wide band and narrow lines, \\ related with host and oxide luminescence, respectively. Temperature dependences of the dielectric permittivity of \\ composites showed the impact of the oxide particles on the characteristics of the microcrystalline cellulose. An \\ assumption was made that this influence can be affected via water molecules, hydroxyl groups or molecules of the \\ ambient gases. Studied composites can be perspective luminescent materials for transformation of ultraviolet and \\ violet radiation into green-red light.
}

DOI: 10.12693/APhysPolA.133.838

PACS/topics: 77.22.Ch, 78.55.-m, 78.66.Sq

\section{Introduction}

New demand for environmental and human friendly modern materials has emerged for last two decades. Composites based on polymer host and incorporated with some micro/nanosized organic or inorganic compounds are advanced materials, as they provide many additional advantages. Cellulose polymers are among them as they are sustainable and renewable materials and micro/nanosized cellulose based materials last time paid great attention due to their perceptiveness for biomedical applications (membranes and filters, scaffolds, antimicrobial films, pharmaceuticals, drugs delivery, etc.) [1-4]. At the same time, they are of interest as materials for applications in electronic and opto-electronic devices, e.g. such as solar cells, supercapacitors, lithium-ion batteries, flexible "paper" electronics [5-7] and luminescent materials [8-10] particularly for their potential applications as chemical and biological sensors or for toxic chemical removing [11-13].

Cellulose is a natural hydrophilic polymer that consist of anhydro-D-glucose units connected by $\beta-1,4$ glycosidic bond and having hydroxyl $(-\mathrm{OH})$ groups which enable cellulose to strong hydrogen bonding.

As for the microcrystalline cellulose (MCC), it is pure partially depolymerised cellulose. The linear cellulose chains are connected as microfibril spiralled together in

\footnotetext{
*corresponding author; e-mail: maxnedel@ukr.net
}

the walls of plant cell. Each microfibril shows a high degree of three-dimensional internal bonding that result in a crystalline structure. Besides, there is some part of the microfibril with weaker internal bonding. They form amorphous regions of cellulose. Micro/nanoscale cellulose materials are characterized by unique and important physical and chemical properties $[14,15]$, which can be modified by incorporation of various additives. Incorporation of inorganic luminescent additive is of special interest and, as has been shown in previously published papers (e.g. [16-19]), were studied in many cases.

The aim of this work is to study properties of the firstly made composite materials that consist of micro/nanoscale cellulose host, MCC, embedded with micro/nanoscale complex oxide, lanthanum orthovanadate, $\mathrm{LaVO}_{4}$, doped with active in luminescence triple-charged samarium ions, $\mathrm{Sm}^{3+}$. We denote below these composites as "MCC- $\mathrm{LaVO}_{4}: \mathrm{Sm}$ ". It was found earlier that the properties of similar cellulose-oxide composite materials depend on the samples morphology, size of components and their distribution over the sample, etc., in other words, they depend on composition and technology of the samples preparation. Composites under this study were made firstly by so-called cool-pressing method [16]. Various properties had to be investigated and various methods were applied, e.g. scanning electron microscopy (SEM), chemical elements analysis, X-ray diffractometry (XRD), luminescence and dielectric spectroscopy. Particular attention was paid to the manifestation of the interaction between the cellulose matrix and the oxide filler. 


\section{Experimental details}

\subsection{The samples}

The chemically pure microcrystalline cellulose (MCC) tablets, manufactured at ANCYR-B (Ukraine), were used as starting material for preparation of the cellulosebased composites. The MCC tablets were dispersed, dissolved in ethanol of high purity and undergone to ultrasonic treatment. The suspension was filtered via paper filter. After that, the powder was dried at ambient air conditions and temperature $T=60^{\circ} \mathrm{C}$. A certain amount of previously prepared and dried micro/nanosized oxide powder was added. Each mixture was stirred in agate mortar until homogeneity (on the eye) was reached. Finally, each portion was divided into 3 parts and each of them was separately undergone to compression at high pressure near $1.8 \times 10^{4} \mathrm{kPa} / \mathrm{m}^{2}$. Therefore, there were $\mathrm{C} 0$ samples (amount of oxide was zero), $\mathrm{C} 1$ samples (1 mg of oxide per $450 \mathrm{mg}$ of MCC), C2 samples (10 mg of oxide per $450 \mathrm{mg}$ of MCC), C3 samples (100 mg of oxide per $450 \mathrm{mg}$ of MCC).

Doped with samarium ions, $\mathrm{Sm}^{3+}$, lanthanum orthovanadate, $\mathrm{LaVO}_{4}: \mathrm{Sm}$, was used as oxide component of the composites. The particles possess average size $0.1-$ $0.2 \mu \mathrm{m}$. Details of the $\mathrm{La}_{1-x} \mathrm{Sm}_{x} \mathrm{VO}_{4}(0 \leq x \leq 0.5)$ samples oxides preparation and sol-gel synthesis can be found in [20]. Previously we have also found that $\mathrm{La}_{1-x} \mathrm{Sm}_{x} \mathrm{VO}_{4}$ luminescence is undergone to concentration quenching. Therefore, the $\mathrm{La}_{0.7} \mathrm{Sm}_{0.3} \mathrm{VO}_{4}$ composition which showed the higher PL intensity was selected for further experiments.

\subsection{Equipment}

The X-ray diffractometry study was performed using a conventional powder diffractometer DRON-3M equipped with BSV-28 tube $\left(\lambda_{\text {rad }}=1.54178 \AA\right)$ and operating in the Bragg-Brentano $(\theta / 2 \theta)$ geometry. The XRD patterns were obtained in the $(2 \theta)$ diffraction angle range 10-70 $0^{\circ}$ with $0.1^{\circ}$ step.

Scanning electron microscopy was performed by means of the JAMP-9500F Field Emission Auger Microprobe (JEOL, USA) equipped with X-ray microanalyzer INCA PentaFetx3 (Oxford Instruments). Microelements analysis at various zones of the samples was also performed using this microscope.

The photoluminescence (PL) and the PL excitation spectra were measured at spectrometric complex SDL$2 \mathrm{M}$ which contains exciting (MDR-12) and registering (MDR-23) monochromators equipped with diffraction grates and photomultipliers. The $\mathrm{N}_{2}$ laser (generation wavelength, $\left.\lambda_{e m}=337.1 \mathrm{~nm}\right)$, diode-pumped lasers $\left(\lambda_{e m}=405,473\right.$, and $\left.532 \mathrm{~nm}\right)$ and Xenon lamp (DXeSh150) have been used for the PL excitation.

Capacity and dielectric losses index of the cell were carried out at $5,10,20$, and $50 \mathrm{kHz}$ frequencies $(f)$ in temperature range $-180-130^{\circ} \mathrm{C}$. Computer controlled homemade equipment on the base of the Đ5083 alternate current bridge was used for these measurements.

\section{Results and discussion}

\subsection{Morphology and structure}

Samples surfaces were scanned by electron microscopy tools. Figure 1 is one of the typical images (sample C2). We can see that the sample consist of many tightly packed plates with size of $2-5 \mu \mathrm{m}$. The crannies can be seen between the plates in some cases (e.g., see in left part of Fig. 1). There is also a certain number of craters/caverns somewhere within the plates. They look like black inlays up to $200 \mathrm{~nm}$ of size in Fig. 1. In addition, some inclusions of a different shape, like grains of white colour, can be seen in Fig. 1. Their sizes are within 10-100 $\mathrm{nm}$ range. The conglomerates of such particles, obviously, form large grains up to $2 \mu \mathrm{m}$ in size. The largest of them is marked with the rectangle \#4 in Fig. 1. The small particles are located in the body of plates, while large grains lie on the plate's surface.

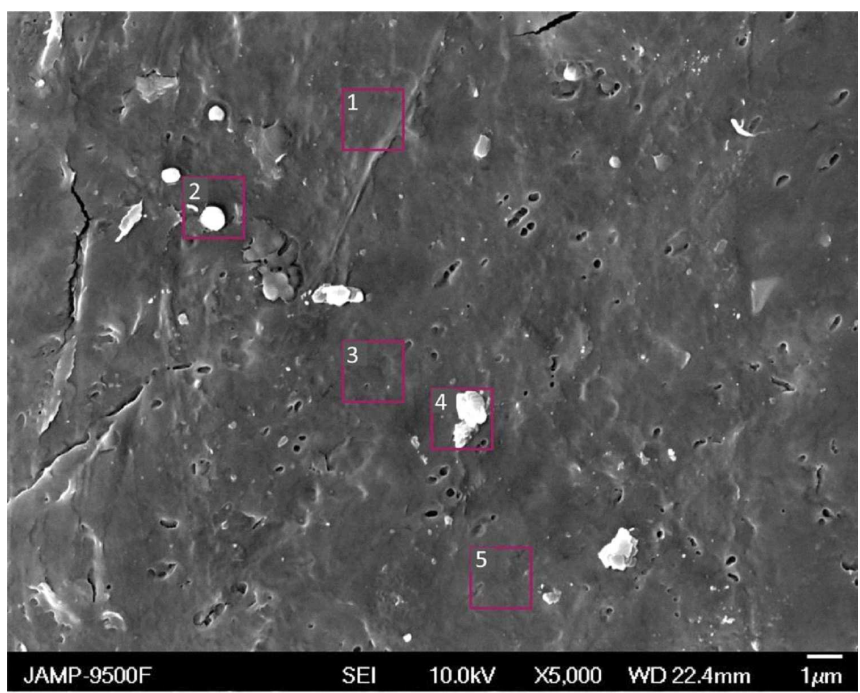

Fig. 1. SEM image of the $\mathrm{C} 2$ composite; rectangular shows regions where chemical analysis was performed.

Chemical elements analysis was performed for several zones of the samples when SEM studies were carried out. Those zones are marked by rectangular in Fig. 1. Carbon (C) and oxygen $(\mathrm{O})$ are dominant in the zones of plate (see zone 1,3 , and 5 ). In these zones the average content of $\mathrm{C}$ and $\mathrm{O}$ was near 70 and 28 at.\%, respectively. Therefore, we conclude that the plates are constructed from MCC host. It is obvious that oxide particles are concentrated in some areas of the samples (see, e.g., zones 2 and 4). The composition of the white particles and their conglomerates is close to the formulae $\mathrm{La}_{0.7} \mathrm{Sm}_{0.3} \mathrm{VO}_{4}$. Really, average content of the La, Sm, V, and O in these zones was near $11.2,5.8,16.9$, and 65.8 at.\%, respectively.

Thus, we can describe made by us "MCC-oxide" micro/nano composites as "ceramics-like" materials where cellulose plates and oxide particles should be subjected to mutual influence and this circumstance could be manifested in the properties of the composites. 


\section{2. $X R D$ analysis}

The XRD pattern of the samples under study showed two sets of diffraction peaks. Relatively wide peaks located at $16.0,22.5$, and $34.5^{\circ}$ of $2 \theta$ reflect characteristics of the MCC host [16, 21, 22]. Others peaks are caused by the $\mathrm{La}_{1-x} \mathrm{Sm}_{x} \mathrm{VO}_{4}$ component [20].

Index of the cellulose crystallinity $(k)$ was calculated on the base of XRD results [16]. Calculated values of $k$ (in \%) were near $60,58,57$, and 56 for the starting $\mathrm{C} 0$ and composite samples $\mathrm{C} 1, \mathrm{C} 2$, and $\mathrm{C} 3$, respectively. These data show effect of oxide particles on the structure and morphology of the cellulose host. Surely, additional experiments are needed to understand on molecular level the mechanisms of this effect. Detailed description of procedure of the similar composites XRD data analysis can be found in [16].

\subsection{Luminescent properties}

Before discussion of the $\mathrm{MCC}-\mathrm{LaVO}_{4}: \mathrm{Sm}$ composites luminescence properties, it worth noting that detailed data and analysis of the luminescence properties both of starting cellulose and LaVO4:Sm oxides can be found in our previous works [16] and [20], respectively. The PL of the MCC-LaVO $\mathrm{MSm}_{4}$ composites was studied under excitations in the spectral range from UV $(250 \mathrm{~nm})$ to yellow light $(570 \mathrm{~nm})$ (Figs. 2, 3). The PL spectra under these excitations consist both of wide band that extends from 350 up to $750 \mathrm{~nm}$ and the set of relatively narrow lines located on the mentioned wide band (Fig. 2). Contribution of wide band, as well as narrow lines to the total spectra depends on the excitation wavelength and on the composition of the sample too (see Fig. 2, curves 1, 2 and Fig. 2, curves 5,6). Characteristics of the wide PL band (shape, peak position $-\lambda_{\max }$, intensity) depend on the $\lambda_{e x}$. We can conclude that at least four components form the wide band. Contributions of these components to the total spectra depend on the $\lambda_{e x}$ and they vary when content of the oxide varies, too (Fig. 2, curves 5,6 ).

Spectra of PL excitation demonstrate complex structure and similarly to the PL spectra they consist of several wide bands, if luminescence is registered at wavelength $\left(\lambda_{e m}\right)$ located in the range of the wide PL band (Fig. 3, curve 1). If the PL is registered in the vicinity of the PL lines, the relatively narrow details of the excitation spectra also arise (Fig. 3, curves 2,3).

The described data are similar to ones earlier reported by us for the microcrystalline cellulose samples and some other "cellulose-oxide" composites $[12,13,16]$. Besides, mentioned characteristics are similar to those published elsewhere concerning luminescence of various cellulosebased materials [5, 8-10].

We can conclude that the wide PL band and wide bands in excitation spectra are caused by luminescence excitation and radiation processes in cellulose host. The complex structure of the cellulose PL is usually caused by presence of several types of molecular fluorophores [810]. Up to now there are no direct relations between the luminescence band components and type of MCC

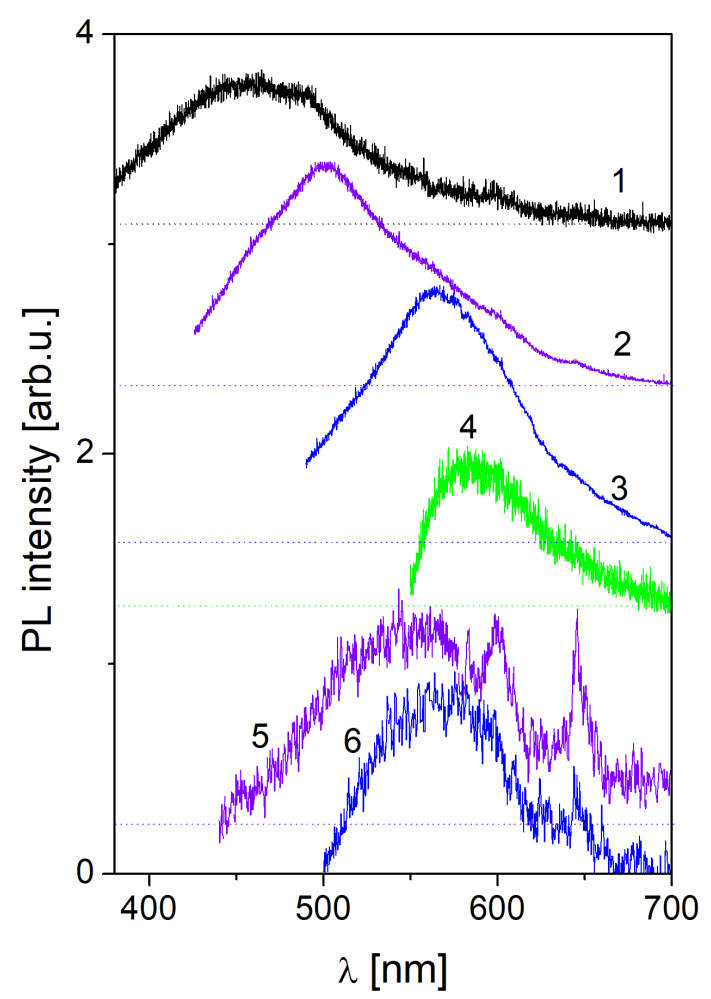

Fig. 2. PL spectra of $\mathrm{C} 2(1-4)$ and $\mathrm{C} 3$ composites $(5,6) ; \lambda_{e x}=337.1$ (1), 405 (2), 408 (5), 473 (3), 477.8 (6) and $532 \mathrm{~nm}(4), T=300 \mathrm{~K}$. Zero signal levels for spectra $1-5$ are shown by dotted lines.

molecular constituents or its derivatives (e.g., carbonyl groups), but the role of the molecular radicals located on the surface of cellulose microfibrils had been already emphasized. Besides, hydroxyl groups located on the surface promote organic molecules adsorption that results in enhancement of the PL [9, 10]. Thus, oxide micro/nanoparticles embedded into cellulose have to change characteristics of the MCC host luminescence. If amount of oxide increases, the narrow PL lines become more intensive, while MCC host luminescence decreases (Fig. 2, curves 5,6$)$. It is easy to conclude that the additive narrow PL lines and lines in excitation spectra are related with $\mathrm{Sm}^{3+}$ ions. In fact, the positions of these groups of lines, their shapes and distribution of their intensity coincide with absorption and emission lines of the $\mathrm{Sm}^{3+}$ ions in various crystalline [20, 23-25], glass-like hosts [26, 27], and liquids [28]. Therefore, we can state that the observed PL groups of lines are due to radiation transitions ${ }^{4} G_{5 / 2} \rightarrow{ }^{6} H_{9 / 2},{ }^{6} H_{7 / 2},{ }^{6} H_{5 / 2}$ from excited ${ }^{4} G_{5 / 2}$ level to the lowest levels of the ground ${ }^{6} H$ state [29-33].

Decrease of the cellulose host PL intensity, when content of the oxide increases, can be ascribed to effect of the oxide micro/nanoparticles on the morphology, composition and dynamics of the molecular groups located on the cellulose microfibrils surface. On the other hand, we found that ratio of the ${ }^{4} G_{5 / 2} \rightarrow{ }^{6} H_{5 / 2},{ }^{6} H_{7 / 2}$, and ${ }^{6} H_{9 / 2}$ 


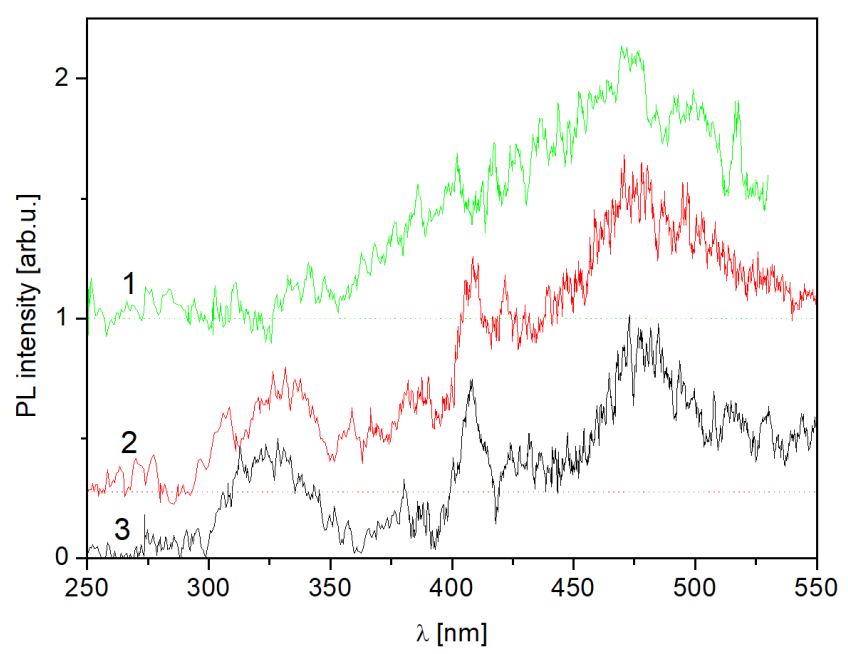

Fig. 3. PL excitation spectra of C3 composites, $\lambda_{e m}=$ 560 (1), 600 (2), and $644.6 \mathrm{~nm}(3), T=300 \mathrm{~K}$. Zero signal levels for spectra 1 and 2 are shown by dotted lines.

transitions intensity in the case of composites differs from one corresponding to "free" $\mathrm{La}_{0.7} \mathrm{Sm}_{0.3} \mathrm{VO}_{4}$ powder [20]. The possibility of such influence is explained, first of all, by the fact that $\mathrm{Sm}^{3+}$ ion in the nanosized $\mathrm{LaVO}_{4}: \mathrm{Sm}$ particles can be located both in the volume and on the surface of particles [20]. The $\mathrm{Sm}^{3+}$ ions "at surface" can be sensitive to the effects of the cellulose surface molecular groups. It is obvious that the amount of such interaction increases with the oxide content in the composite that leads to the observed spectral changing.

Described below data about effect of oxide particles on dielectric properties of made composites also confirm the role of the cellulose-oxide interfaces.

\subsection{Dielectric properties}

Temperature dependences of the real $\left(\varepsilon^{\prime}\right)$ and imaginary $\left(\varepsilon^{\prime \prime}\right)$ parts of the complex dielectric permittivity $\left(\varepsilon^{*}\right)$ taken at different frequencies of the probing electromagnetic field are shown in Fig. 4. If compare these dependences with the similar data concerning pure MCC (see e.g. [4]), it is easy to find that general view of these curves is similar. If we describe $\left(\varepsilon^{\prime}, \varepsilon^{\prime \prime}\right)$ dependences for the "MCC-oxide" composites, then the next differences should be noted compared to the pure MCC samples. First, analyzing the data for composite with lowest amount of oxide ( $\mathrm{C} 1$ sample), we see failures in the ranges $-160-70{ }^{\circ} \mathrm{C}$ for the $\varepsilon^{\prime}$ curve measured at $f=5 \mathrm{kHz}$ (Fig. 4a). Accordingly, additional peaks aroused on the corresponding $\varepsilon^{\prime \prime}$ curve in the noted temperature range (Fig. $4 \mathrm{~b}$ ). The $\varepsilon^{\prime \prime}$ in the maximum of high temperature peak reaches the value near 0.4 , which exceeds corresponding value for the case of pure MCC (0.14) in 2.85 times. Both the failure and peaks significantly decrease when the following temperature measurements were performed at probing frequency $f=50 \mathrm{kHz}$ (Fig. 4a,b). Second, it should be pointed out that if the content of oxide increases very strongly (in 100 times for the sample C3) the low temperature failure on the $\varepsilon^{\prime}$ and corresponding peaks on the $\varepsilon^{\prime \prime}$ dependences also diminish. Undoubtedly, described peculiarities of the $\left(\varepsilon^{\prime}, \varepsilon^{\prime \prime}\right.$ behaviour are the result of the oxide particles influence on the MCC properties.
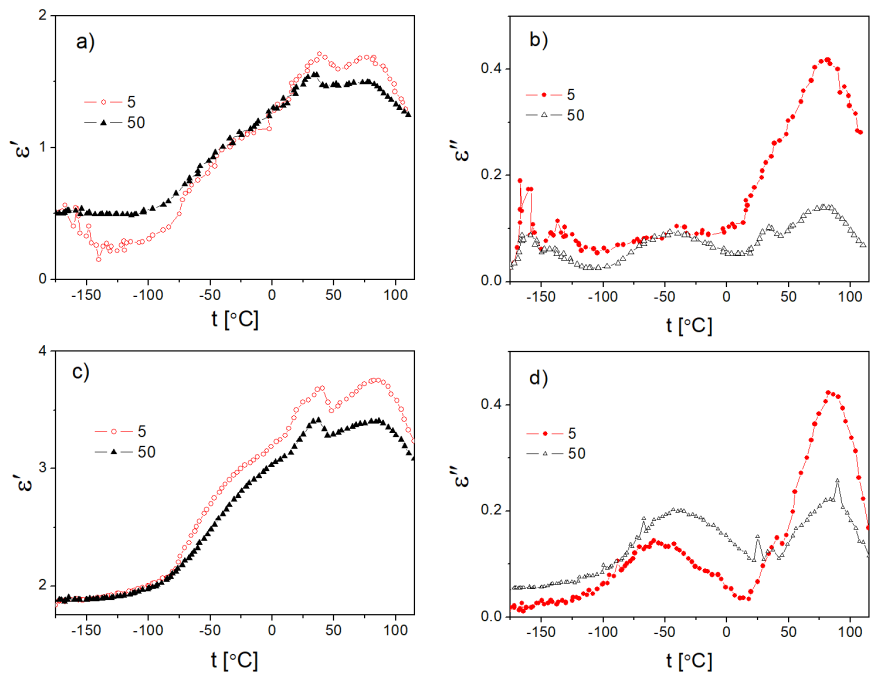

Fig. 4. Real (a,c) and imaginary (b,d) parts of dielectric permittivity of the $\mathrm{C} 1(\mathrm{a}, \mathrm{b})$ and $\mathrm{C} 3$ composites $(\mathrm{c}, \mathrm{d})$ at frequencies 5 and $50 \mathrm{kHz}$.

Two types of effects can be distinguished, we suppose. First of them determines changes of the $\left(\varepsilon^{\prime}, \varepsilon^{\prime \prime}\right)$ in the temperature ranges $-160-70^{\circ} \mathrm{C}$ and $25-130^{\circ} \mathrm{C}$. Only $\left(\varepsilon^{\prime}\right.$, $\left.\varepsilon^{\prime \prime}\right)$ values change in these range under frequency and oxide content increase, while there is no shifts of the $\left(\varepsilon^{\prime}, \varepsilon^{\prime \prime}\right)$ curves in these temperature ranges. Besides, when the oxide is added, we see changes in a different sign in these temperature ranges. Therefore, we assume that oxide particles impact on two kinds of surface MCC molecular groups and their responses on this influence are different. Thus, we think that some amount of water molecules, hydroxyl groups and ambient gases are incorporated into MCC host as have been adsorbed on the surface of oxide particles. Then, they bind to surface MCC molecular groups that either decreases $\left(-160-70^{\circ} \mathrm{C}\right.$ temperature range) either increases $\left(25-130^{\circ} \mathrm{C}\right.$ range) the dipole moment (polarizability) of the samples under study and, consequently, corresponding changes in the dielectric permittivity occur. Observed consistent changes of the $\left(\varepsilon^{\prime}\right.$, $\left.\varepsilon^{\prime \prime}\right)$ values in these ranges with step-by-step changes of probing frequency $(5,10,20$, and then $50 \mathrm{kHz})$ can be caused by consecutive temperature treatment of the sample. Namely, each heating from -180 up to $130^{\circ} \mathrm{C}$ can result in changes of sample composition, e.g., caused by removing of water and some ambient gases.

As for $\left(\varepsilon^{\prime}, \varepsilon^{\prime \prime}\right)$ curves in the temperature ranges -125$25^{\circ} \mathrm{C}$, we have to note that their temperature and frequency behaviour over there are typical for molecular reorientations occurring as over-barrier temperature tran- 
sitions between two equilibrium positions of molecular groups. We can assume that relaxation which is observed on real and imaginary parts of dielectric permittivity $\varepsilon^{\prime \prime}$ in this temperature range reveals reorientation of methyl groups from $t g$ to $t t$ conformation on the microfibrils surface.

Fitting experimental $\varepsilon^{\prime}(T, f)$ dependences (Fig. 4) with theoretical Debye approximation, we were able to evaluate the energy barrier between equilibrium positions. Corresponding values are 46,62 , and $87 \mathrm{~kJ} / \mathrm{mol}$ for the $\mathrm{C} 1, \mathrm{C} 2$, and C3 samples, respectively. These data manifest the trend of noted parameters to be higher if amount of the oxide increases.

\section{Conclusions}

The set of the composite samples which consist of micro/nanocrystalline cellulose host and embedded micro/nanoparticles of complex oxide, $\mathrm{La}_{0.7} \mathrm{Sm}_{0.3} \mathrm{VO}_{4}$, were made by cool pressing procedure and their properties and characteristics were studied and evaluated. Their morphology can be classified as "ceramics-like" type, as the ensemble of cellulose plates and embedded between them or into them oxide particles were revealed.

The composites showed intensive both wide band and narrow lines luminescence in the entire range of visible light 350-750 $\mathrm{nm}$ and this luminescence can be excited in the range $250-550 \mathrm{~nm}$. That is why, these composites are perspective for creation on their base of luminescent transformers of ultraviolet and violet radiation to white light.

Studied composites are not ordinary mechanical mixture of the cellulose host and oxide compounds. The luminescent findings manifested effect of cellulose on the electronic energy system of the $\mathrm{Sm}^{3+}$ ion and measured the PL characteristics. On the other hand, behaviour of the dielectric permittivity of the cellulose host showed impact of the oxide particles on the characteristics of the microcrystalline cellulose. An assumption was made that this influence can be affected via water molecules, hydroxyl groups or molecules of the ambient gases.

\section{Acknowledgments}

The authors are grateful to the head of the group of chemists, Prof. S.A. Nedilko, and employees of this group Ph.D. T. Voitenko and postgraduate student A. Slepets for their work on the oxide materials synthesis.

\section{References}

[1] A. Kumar, Yu.S. Negi, V. Choudhary, N.K. Bhardwaj, J. Mater. Phys. Chem. 2, 1 (2014).

[2] R.J. Moon, A. Martini, A. Nairn, J. Simonsen, J. Youngblood, Chem. Soc. Rev. 40, 3941 (2011).

[3] I. Siro, D. Plackett, Cellulose 17, 459 (2010).

[4] S. Ummartyotin, C. Pechyen, Carbohydr. Polym. 142, 133 (2016)

[5] M. Karakawa, M. Chikamatsu, C. Nakamoto, Y. Maeda, S. Kubota, K. Yase, Macromol. Chem. Phys. 208, 2000 (2007).
[6] S. Yun, S.D. Jang, G.Y. Yun, J.H. Kim, J. Kim, Appl. Phys. Lett. 95, 104102 (2009).

[7] N. Wang, E. Ding, R. Cheng, Langmuir 24, 5 (2008).

[8] R.P. Bateh, J.D. Winefordner, Talanta 29, 713 (1982).

[9] V. Pikulev, S. Loginova, V. Gurtov, Nanoscale Res. Lett. 7, 426 (2012).

[10] H. Tylli, I. Forsskahl, C. Olkkonen, Cellulose 7, 133 (2000).

[11] Z. Zhou, Q. Wang, Sens. Actuat. B 173, 833 (2012).

[12] S. Nedilko, S. Revo, M. Nedielko, T. Avramenko, K. Ivanenko, V. Scherbatskii, Solid State Phenom. 230, 147 (2015)

[13] S.G. Nedilko, S.L. Revo, V.P. Chornii, V.P. Scherbatskyi, M.S. Nedielko, J. Sens. Sens. Syst. 4, 31 (2015).

[14] S.S.Z. Hindi, Biocryst. J. 1, 26 (2016).

[15] A. Dufresne, Mater. Today 16, 220 (2013).

[16] M. Nedielko, S. Hamamda, O. Alekseev, V. Chornii, M. Dashevskii, M. Lazarenko, K. Kovalov, S.G. Nedilko, S. Tkachov, S. Revo, V. Scherbatskyi, Nanoscale Res. Lett. 12, 98 (2017).

[17] P. Kulpinski, A. Erdman, T. Grzyb, S. Lis, Polym. Compos. 37, 153 (2016)

[18] E. Smiechowicz, P. Kulpinski, B. Niekraszewicz, A. Bacciarelli, Cellulose 18, 975 (2011).

[19] P. Kulpinski, A. Erdman, M. Namyślak, J.D. Fidelus, Cellulose 19, 1259 (2012).

[20] V. Chornii, O. Chukova, S.G. Nedilko, S.A. Nedilko, T. Voitenko, Phys. Status Solidi C 13, 40 (2016).

[21] C. Driemeier, G.A. Calligaris, J. Appl. Crystallogr. 44, 184 (2011).

[22] K. Leppeanen, S. Andersson, M. Torkkeli, M. Knaapila, N. Kotelnikova, R. Serimaa, Cellulose 16, 999 (2009).

[23] X. Liu, Y. Zhang, Z. Wang, Sh. Lu, J. Lumin. 40-41, 885 (1988).

[24] M. Malinowski, B. Jacquier, G. Boulon, J. Lumin. 39, 301 (1988).

[25] M.J. Treadaway, R.C. Powell, Phys. Rev. B 11, 862 (1975).

[26] J. Maa, M. Wollenhaupt, H. Abrens, P. Fröbel, K. Bärner, J. Lumin. 62, 95 (1994).

[27] Z. Zhang, X. Jiang, Z. Li, P. Wu, J. Lumin. 40-41, 657 (1988).

[28] M. Elbanowski, S. Lis, B. Makowska, J. Konarski, Monatsh. Chem. 116, 901 (1985).

[29] A.H. Reshak, S. Azam, Int. J. Electrochem. Sci. 8, 10396 (2013).

[30] M. Sobszyk, D. Szymański, J. Lumin. 142, 96 (2013).

[31] B.G. Wybourne, Spectroscopic Properties of Rare Earth, Wiley-Interscience, New York 1965.

[32] G. Boulon, Rev. Phys. Appl. 21, 689 (1986).

[33] S. Hufner, in: Systematics and Properties of the Lanthanides, Ed. S.P. Sinha, D. Reidel Publ. Co., Dordrecht 1983, p. 313 